\title{
Common variant rs7579169 is associated with preeclampsia in Han Chinese women
}

\author{
L.F. Guo, Z.H. Wang and Y.F. Wang \\ Department of Obstetrics and Gynecology, Suzhou Xiangcheng People's Hospital, \\ Suzhou, China \\ Corresponding author: L.F. Guo \\ E-mail: 383570047@qq.com \\ Genet. Mol. Res. 15 (2): gmr.15028114 \\ Received November 24, 2015 \\ Accepted January 8, 2016 \\ Published May 6, 2016 \\ DOI http://dx.doi.org/10.4238/gmr.15028114
}

\begin{abstract}
As a heterogeneous group of disorders in pregnancy, many genetic factors are involved in the development of preeclampsia. The single nucleotide polymorphism (SNP) rs7579169, located on chromosome $2 \mathrm{q} 14.2$, has been shown to be associated with pregnancyinduced hypertension in Europeans. In this study, we examined whether the SNP rs7579169 is associated with the susceptibility to preeclampsia through a case-control research model in Han Chinese women. Genotypes of 145 patients with preeclampsia and 150 healthy pregnant subjects were identified by direct sequencing. The correlation between the rs7579169 genotype and the susceptibility to preeclampsia was evaluated using an unconditional logistic regression model. Although there were no differences of having the rs7579169 SNP between early onset and late onset preeclampsia, patients carrying the CT or TT genotype were more likely to develop preeclampsia than those carrying the $\mathrm{CC}$ genotype $(\mathrm{CT} v s \mathrm{CC}$ : $\mathrm{OR}=1.76,95 \% \mathrm{CI}=1.07-2.87, \mathrm{P}<0.05$; TT vs CC: $\mathrm{OR}=5.03,95 \% \mathrm{CI}=1.99-12.73, \mathrm{P}<0.05 ; \mathrm{CC} v_{\mathrm{S}} \mathrm{CT}+\mathrm{TT}$ : $\mathrm{OR}=2.05,95 \% \mathrm{CI}=1.27-3.30, \mathrm{P}<0.05)$. In conclusion, although no differences of the rs7579169 SNP were identified between the early onset and late onset preeclampsia groups, we found that the CT or TT
\end{abstract}


genotype and the $\mathrm{CT}+\mathrm{TT}$ genotype were significantly associated with an increased risk of preeclampsia in Han Chinese women.

Key words: Preeclampsia; rs7579169; Single nucleotide polymorphism

\section{INTRODUCTION}

Preeclampsia is a heterogeneous group of disorders in pregnancy with de novo hypertension and proteinuria occurring after the 20th gestational week and is characterized by hypertension and proteinuria, with or without edema (Haram et al., 2014). As one of the most common pregnancy complications, preeclampsia is a mainly cause of high mortality and morbidity of both mother and child (Aali et al., 2004; Langenveld et al., 2011). Nowadays, more studies have focused on the subject of genetic conditioning of preeclampsia, but the etiology of preeclampsia is still unknown (Molvarec et al., 2008).

Single nucleotide polymorphisms (SNPs) can be an insertion, deletion, or substitution point mutation in the coding or noncoding DNA sequence (Kuśmierska-Urban et al., 2015), with an increasing number being identified to associate with risks and prognoses of human diseases (Shastry, 2009). A genome-wide association study (GWAS) of preeclampsia had reported a risk locus on chromosome 2q14 (Johnson et al., 2012); subsequently, the SNP rs7579169, located on chromosome 2 q14.2, has been shown to be associated with pregnancyinduced hypertension in Europeans (Kuśmierska-Urban et al., 2015). In this study, we aimed to identify the association between preeclampsia and the SNP rs7579169 in a cohort of Han Chinese women.

\section{MATERIAL AND METHODS}

\section{Study subjects}

The study subjects consisted of 145 patients with preeclampsia and 150 healthy pregnant subjects, randomly selected from the Suzhou Xiangcheng People's Hospital between 2009 and 2015. Preeclampsia is defined as gestational hypertension with proteinuria (the presence of blood pressure values ${ }^{3} 140 / 90 \mathrm{mmHg}$ on two measurements at least $6 \mathrm{~h}$ apart; $24 \mathrm{~h}$ urinary protein ${ }^{3} 300 \mathrm{mg}$ or a protein-positive urine dipstick test) after the 20th week of pregnancy in a previously normotensive and non-proteinuric woman (Wan et al., 2013). Patients with multiple pregnancies, fetal anomalies, and with renal, liver, or heart diseases were excluded. Each patient was interviewed and a detailed medical history such as gravidity, parity, fetal weight, pre-pregnancy body mass index (pre-BMI), and week of gestation was taken. Early-onset preeclampsia was defined as manifestation before 34 gestational weeks and late-onset preeclampsia as thereafter.

After written consent, peripheral vein blood was obtained from each study subject. The protocol was approved by the Ethics Committee of the Suzhou Xiangcheng People's Hospital.

\section{DNA extraction and genotyping}

Wizard Genomic DNA Purification Kit (Promega, Madison, WI, USA) was used 
to extract genomic DNA from peripheral blood and tumor tissues, respectively (Shen et al., 2015). After PCR amplication, the products were sequenced directly by ABI 3730. The primers were: forward primer: 5'-CTGCTCTATGGCTTCCCAAG-3'; reverse primer: 5'-TGAGCGAACTCAGGCACA-3'. The PCR conditions were: $95^{\circ} \mathrm{C}$ for $5 \mathrm{~min}$, then 40 cycles at $95^{\circ} \mathrm{C}$ for $30 \mathrm{~s}, 55^{\circ} \mathrm{C}$ for $30 \mathrm{~s}$, and $72^{\circ} \mathrm{C}$ for $30 \mathrm{~s}$, followed by $72^{\circ} \mathrm{C}$ for $5 \mathrm{~min}$ (KuśmierskaUrban et al., 2015).

\section{Statistical analysis}

The SAS version 17.0 software was used for statistical analysis (SAS Institute, Cary, NC, USA). All statistical tests were two-sided, and differences were considered to be statistically significant when $\mathrm{P}<0.05$. Furthermore, after adjusted by age and gender, odds ratios (ORs) and 95\% confidence intervals $(95 \% \mathrm{CI})$ from a non-conditional logistic regression model were used to estimate the association between rs 7579169 genotypes and susceptibility to preeclampsia.

\section{RESULTS}

\section{Characteristics of cases}

Included in this study were 145 patients with preeclampsia (81 were early-onset, 64 were late-onset) and 150 healthy pregnant subjects. The characteristics of the subjects are shown in Table 1. Maternal age, pre-BMI and primiparas were matched in case and control groups $(\mathrm{P}>0.05)$. SBP (systolic blood pressure) and DBP (diastolic blood pressure) were higher in the case group than in the control group (SBP: $160.5 \pm 20.5$ vs $111.5 \pm 9.8$; DBP: $108.1 \pm 13.3$ vs $78.6 \pm 6.7 \mathrm{mmHg}$ ). Due to preeclampsia, delivery weeks were early in the case group than in the control group ( $35.8 \pm 2.9 v s 39.5 \pm 1.2)$. Fetal weight was lower in the case group than in the control group (2548.6 $\pm 955.4 v s 3403.2 \pm 564.9 \mathrm{~g})$.

Table 1. Basic characteristics of study subjects.
\begin{tabular}{l|c|c|c}
\hline Variable & Patients (N $=145)$ & Controls (N = 150) & P value \\
\hline Maternal age (years) (mean \pm SD) & $27.9 \pm 5.2$ & $29.2 \pm 5.4$ & $>0.05$ \\
\hline Pre-BMI & $24.8 \pm 3.0$ & $23.1 \pm 2.8$ & $>0.05$ \\
\hline Primiparas & $75(51.7)$ & $80(53.3)$ & $>0.05$ \\
\hline SBP (mmHg) & $160.5 \pm 20.5$ & $711.5 \pm 9.8$ & $<0.05$ \\
\hline DBP (mmHg) & $108.1 \pm 13.3$ & $39.6 \pm 6.7$ & $<0.05$ \\
\hline Delivery weeks & $35.8 \pm 2.9$ & $3403.2 \pm 564.9$ & $<0.05$ \\
\hline Fetal weight (g) & $2548.6 \pm 955.4$ & & $<0.05$ \\
\hline Early-onset & $81(55.9)$ & & \\
\hline Late-onset & $64(44.1)$ & & \\
\hline
\end{tabular}

\section{Genotyping and association analysis}

Genotyping of the rs7579169 SNP from all samples was successfully determined by direct sequencing. After analysis with the Hardy-Weinberg equilibrium $(\mathrm{P}=0.4591$ and 0.1281 , respectively), all data were used for further analysis.

As shown in Table 2, in the preeclampsia group, 45/145 (31.0\%) were CC homozygotic, 78/145 (53.8\%) were CT heterozygotic, while 22/145 (15.2\%) were TT homozygotic. In 
control samples, the frequency of the CC, CT, and TT genotypes were 48, 47.3, and 4.7\%, respectively. By logistic regression analysis, we found significant differences in susceptibility to preeclampsia $(\mathrm{CT}$ vs $\mathrm{CC}: \mathrm{OR}=1.76,95 \% \mathrm{CI}=1.07-2.87, \mathrm{P}<0.05$; $\mathrm{TT}$ vs $\mathrm{CC}: \mathrm{OR}=5.03$, $95 \% \mathrm{CI}=1.99-12.73, \mathrm{P}<0.05 ; \mathrm{CC} v s \mathrm{CT}+\mathrm{TT}: \mathrm{OR}=2.05,95 \% \mathrm{CI}=1.27-3.30, \mathrm{P}<0.05)$. Furthermore, in the early-onset preeclampsia group, 23/81 (28.4\%) were CC homozygotic, 43/81 (53.1\%) were CT heterozygotic, while 15/81 (18.5\%) were TT homozygotic. In the late-onset group, the frequency of the CC, CT, and TT genotypes were 34.4, 54.6, and 7\%, respectively. No significant differences were found between the early onset and late-onset group (Table 3).

\begin{tabular}{|c|c|c|c|c|}
\hline \multirow[t]{2}{*}{ Variables } & Cases $(\mathrm{N}=145)$ & Controls $(\mathrm{N}=150)$ & \multirow[t]{2}{*}{ Odds ratio $(95 \% \mathrm{CI})$} & \multirow[t]{2}{*}{$\mathrm{P}$ value } \\
\hline & {$[\mathrm{N}(\%)]$} & {$[\mathrm{N}(\%)]$} & & \\
\hline \multicolumn{5}{|l|}{ Genotypes } \\
\hline $\mathrm{CC}$ & $45(31.0)$ & $72(48.0)$ & 1 (reference) & \multirow[t]{2}{*}{$<0.05$} \\
\hline $\mathrm{CT}$ & $78(53.8)$ & $71(47.3)$ & $1.76(1.07-2.87)$ & \\
\hline TT & $22(15.2)$ & $7(4.7)$ & $5.03(1.99-12.73)$ & $<0.05$ \\
\hline HWE P* & 0.4591 & 0.1281 & & \\
\hline $\mathrm{CC} v s \mathrm{CT}+\mathrm{TT}$ & & & $2.05(1.27-3.30)$ & $<0.05$ \\
\hline
\end{tabular}

*Hardy-Weinberg equilibrium.

Table 3. Genotype frequencies of rs 7579169 in women with preeclampsia.

\begin{tabular}{l|c|c|c|c}
\hline \multirow{2}{*}{ Variables } & Early-onset $(\mathrm{N}=81)$ & Late-onset $(\mathrm{N}=64)$ & \multirow{2}{*}{ Odds ratio $(95 \% \mathrm{CI})$} & P value \\
\cline { 2 - 4 } & {$[\mathrm{N}(\%)]$} & {$[\mathrm{N}(\%)]$} & 1 (reference) & $>0.05$ \\
\hline Genotypes & $23(28.4)$ & $22(34.4)$ & $1.18(0.56-2.45)$ & $>0.05(0.70-5.98)$ \\
\hline CC & $43(53.1)$ & $35(54.6)$ & & $>05$ \\
\hline CT & $15(18.5)$ & $7(11.0)$ & $1.32(0.65-2.68)$ & $>0.05$ \\
\hline TT & 0.8097 & 0.4529 & & \\
\hline HWE P* & & & & \\
\hline
\end{tabular}

*Hardy-Weinberg equilibrium.

\section{DISCUSSION}

Preeclampsia is currently recognized as a syndrome rather than as a definite disease. Approximately 2.5 to $3 \%$ of all pregnancies are affected and preeclampsia is a leading cause of maternal morbidity and mortality in developing countries (Sibai et al., 1993; de Swiet, 2000). Despite intensive research efforts, the etiology and pathogenesis of preeclampsia are still not fully understood. Increasing evidence suggests that chronic hypertension, renal diseases, obesity and insulin resistance, diabetes mellitus, preexisting thrombophilia, family history of preeclampsia, smoking and high BMI were associated with preeclampsia. As the essential hypertension (EH), preeclampsia was also thought to be a multifactorial disorder that develops due to an interaction of hereditary and environmental factors. Many possible susceptibility genes were reported, such as angiotensin, angiotensin-type 1 receptor, endothelial nitric oxide synthase, estrogen receptor $\beta$, apolipoprotein E, lipoprotein lipase, and methylenetetrahydrofolate reductase (Nakayama and Yamamoto, 2009).

In our study, we found that the rs7579169 SNP was associated with preeclampsia in Han Chinese women. The rs7579169 SNP is located on chromosome 2q14.2, and it has been reported to be associated with preeclampsia in an Australian population (Johnson et al., 
2012) and in a Polish population (Kuśmierska-Urban et al., 2015). The heterozygote CT of the rs7579169 SNP was associated with a 4.5-fold increased risk of preeclampsia, and the CT and TT genotypes were associated with larger weight gain of the mother during pregnancy and an increased risk of fetal hypotrophy. Some studies have suggested that the rs7579169 SNP might affect the expression of the inhibin beta B (INHBB) gene, which is close to the rs7579169 SNP (Kuśmierska-Urban et al., 2015). However, the role of the rs 7579169 SNP in preeclampsia is still unknown. Consistent with the previous studies, we found that the rs7579169 SNP was related to the susceptibility of preeclampsia in Han Chinese women. Patients with the CT or TT genotypes were more likely to develop preeclampsia than those with the CC genotype. No differences in genotypes were found between the early-onset and late-onset preeclampsia groups.

In conclusion, although no differences of the rs7579169 SNP were identified between the early-onset and late-onset preeclampsia groups, we found that the CT or TT genotype and the $\mathrm{CT}+\mathrm{TT}$ genotype were significantly associated with an increased risk of preeclampsia in Han Chinese women. Further investigations including larger populations are needed to confirm our results and to define the potential mechanisms of the rs7579169 SNP in the development of preeclampsia.

\section{Conflicts of interest}

The authors declare no conflict of interest.

\section{REFERENCES}

Aali BS, Ghafoorian J and Mohamad-Alizadeh S (2004). Severe preeclampsia and eclampsia in Kerman, Iran: complications and outcomes. Med. Sci. Monit. 10: CR163-CR167.

de Swiet M (2000). Maternal mortality: confidential enquiries into maternal deaths in the United Kingdom. Am. J. Obstet. Gynecol. 182: 760-766. http://dx.doi.org/10.1016/S0002-9378(00)70324-3

Haram K, Mortensen JH and Nagy B (2014). Genetic aspects of preeclampsia and the HELLP syndrome. J. Pregnancy 2014: 910751. http://dx.doi.org/10.1155/2014/910751

Johnson MP, Brennecke SP, East CE, Göring HH, et al. (2012). Genome-wide association scan identifies a risk locus for preeclampsia on 2q14, near the inhibin, beta B gene. PLoS One 7: e33666. http://dx.doi.org/10.1371/journal. pone. 0033666

Kuśmierska-Urban K, Rytlewski K, Huras H and Wybrańska I (2015). Association of single nucleotide polymorphism rs 7579169 with hypertension disorders during pregnancy and perinatal outcome. Neuroendocrinol. Lett. 36: 282-287.

Langenveld J, Ravelli AC, van Kaam AH, van der Ham DP, et al. (2011). Neonatal outcome of pregnancies complicated by hypertensive disorders between 34 and 37 weeks of gestation: a 7 year retrospective analysis of a national registry. Am. J. Obstet. Gynecol. 205: 540.e1-540.e7. http://dx.doi.org/10.1016/j.ajog.2011.07.003

Molvarec A, Jermendy A, Kovács M, Prohászka Z, et al. (2008). Toll-like receptor 4 gene polymorphisms and preeclampsia: lack of association in a Caucasian population. Hypertens. Res. 31: 859-864. http://dx.doi.org/10.1291/hypres.31.859

Nakayama T and Yamamoto T (2009). Comparison between essential hypertension and pregnancy-induced hypertension: a genetic perspective. Endocr. J. 56: 921-934. http://dx.doi.org/10.1507/endocrj.K09E-253

Shastry BS (2009). SNPs: impact on gene function and phenotype. Methods Mol. Biol. 578: 3-22. http://dx.doi. org/10.1007/978-1-60327-411-1_1

Shen LQ, Xie YZ, Qian XF, Zhuang ZX, et al. (2015). A single nucleotide polymorphism in the promoter region of let-7 family is associated with lung cancer risk in Chinese. Genet. Mol. Res. 14: 4505-4512. http://dx.doi.org/10.4238/2015.May.4.8

Sibai BM, Ramadan MK, Usta I, Salama M, et al. (1993). Maternal morbidity and mortality in 442 pregnancies with hemolysis, elevated liver enzymes, and low platelets (HELLP syndrome). Am. J. Obstet. Gynecol. 169: 1000-1006. http://dx.doi.org/10.1016/0002-9378(93)90043-I

Wan JP, Zhao H, Li T, Li CZ, et al. (2013). The common variant rs11646213 is associated with preeclampsia in Han Chinese women. PLoS One 8: e71202. http://dx.doi.org/10.1371/journal.pone.0071202 